\title{
DEC205 mediates local and systemic immune responses to Helicobacter pylori infection in humans
}

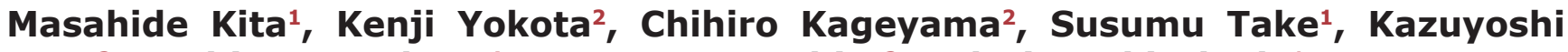 \\ Goto $^{3}$, Yoshiro Kawahara ${ }^{4}$, Osamu Matsushita ${ }^{3}$ and Hiroyuki Okada ${ }^{1}$ \\ ${ }^{1}$ Department of Gastroenterology and Hepatology, Graduate School of Medicine, Dentistry, and Pharmaceutical Science, \\ Okayama University, Okayama, Japan \\ ${ }^{2}$ Graduate School of Health Science, Okayama University, Okayama, Japan \\ ${ }^{3}$ Department of Bacteriology, Graduate School of Medicine, Dentistry, and Pharmaceutical Science, Okayama University, \\ Okayama, Japan \\ ${ }^{4}$ Department of Endoscopy, Okayama University Hospital, Okayama, Japan \\ Correspondence to: Kenji Yokota, email: yokochan@md.okayama-u.ac.jp \\ Keywords: CD14; DEC205; Helicobacter pylori; macrophage; Immunology \\ Received: November 04, 2016 Accepted: October 25, 2017 Epub: February 26, 2018 Published: March 23, 2018
}

Copyright: Kita et al. This is an open-access article distributed under the terms of the Creative Commons Attribution License 3.0 (CC BY 3.0), which permits unrestricted use, distribution, and reproduction in any medium, provided the original author and source are credited.

\section{ABSTRACT}

Helicobacter pylori infections cause gastritis and affect systemic immune responses; however, no direct association between immune cells and stomach bacteria has yet been reported. The present study investigated DEC205-mediated phagocytosis of $\boldsymbol{H}$. pylori and the role of DEC205-positive macrophages in the human gastric mucosa. DEC205 mediated phagocytosis of $\boldsymbol{H}$. pylori was detected immunocytochemically in PMAstimulated macrophages differentiated from NOMO1 cells. Expression of DEC205 mRNA in peripheral blood mononuclear cells (PBMCs) from $\boldsymbol{H}$. pylori-infected patients was analyzed following stimulation with $H$. pylori cell lysate. We found that anti-DEC205 antibodies inhibited phagocytosis of $\boldsymbol{H}$. pylori. The number of cells double-positive for DEC205 and CD14 in human gastric mucosa was higher in $H$. pylori-infected patients. DEC205-positive macrophages invaded the extracellular space between epithelial cells within gastric pits. In addition, DEC205 mRNA expression was upregulated in human PBMCs stimulated with $H$. pylori lysate. These findings suggest DEC205-expressing macrophages are important for recognition of $\boldsymbol{H}$. pylori in human gastric mucosa, which affects systemic immunity.

\section{INTRODUCTION}

Helicobacter pylori is a Gram-negative spiral bacterium that infects the gastric mucosa. It is associated not only with gut diseases such as peptic ulcer, gastric mucosa-associated lymphoid tissue (gastric-MALT) lymphoma, and gastric cancer [1-4], but also with systemic diseases $[5,6]$. The mechanism underlying local and systemic acquired immunity in gastric mucosa remains unclear, although gastric-MALT does not occur in healthy mucosa. In a mouse model, antigen-presenting cells (APCs) such as dendritic cells (DCs) within intestinal Peyer's patches are important for accumulation of CD14-positive cells within gastric mucosa [7], while macrophage-derived cytokine production in the gastric mucosa is strongly upregulated during $H$. pylori infection [8]. These adaptive responses are also characterized by increased lymphocyte and macrophage infiltration of infected gastric tissues $[9,10]$. Thus, macrophages and DCs within the gastric mucosa may play an important role in $H$. pylori-induced acquired immunity. However, the mechanisms underlying $\mathrm{H}$. pylori recognition and its interaction with the gastric mucosa remain unclear.

DEC205 belongs to the mannose receptor family, a subgroup of the C-type lectin superfamily, and is expressed by macrophages, DCs and B cells, as well as by thymic, pulmonary and intestinal epithelia [11]. In DCs, DEC205 functions as an antigen-uptake receptor that targets its cargo to intracellular compartments to be processed for presentation to $\mathrm{T}$ cells $[12,13]$. Human 
DEC205 was initially identified as a $200-\mathrm{kDa}$ glycoprotein (gp200) recognized by the MR6 monoclonal antibody and is expressed by epithelial cells of the thymic cortex, in DCs and, at low levels, in T cells [14]. MR6 was shown to have an anti-proliferative effect on interleukin (IL)-4dependent $\mathrm{T}$ helper 2 immunity [15-17]. DEC205 and gp200 have since been confirmed to be the same molecule based on sequence analysis, and have been designated CD205. However, the distribution of DEC205 within the gastric mucosa has not yet been reported.

In the present study, we investigated the role of DEC205 on macrophages in $H$. pylori infection. The interaction between DEC205 and $H$. pylori was examined using the NOMO-1 human monocyte line, which was stimulated with phorbol 12-myristate 13-acetate (PMA) to induce macrophage differentiation. DEC205-mediated phagocytosis was evaluated using an inhibitory antiDEC205 antibody. In addition, DEC205-positive macrophages were detected in the gastric mucosa of patients with gastritis, and DEC205 mRNA expression in systemic lymphocytes was evaluated. Our results suggest increasing levels of the endocytic receptor DEC205 in local and systemic immune cells of patients with $H$. pylori infection may mitigate gastric inflammation and enhance systemic immunity.

\section{RESULTS}

\section{Phagocytosis of $\boldsymbol{H}$. pylori by macrophages via DEC205}

We first investigated whether DEC205 plays a role in phagocytosis of $H$. pylori. When $H$. pylori cells were labeled with an antibody against urease $(30 \mathrm{kDa})$, an $H$. pylori surface protein, the bacterial cells were observed within the cytoplasm of NOMO-1 cells (Figure 1A). Double labeling revealed cells that were double-positive for urease and DEC205 (Figure 1B). Phagocytosis was perturbed by treating NOMO-1 cells with anti-DEC205, anti-CD14, or anti- $\beta$-actin antibodies prior to $H$. pylori infection (Figure 1C). The number of internalized bacteria was significantly decreased by treatment with antiDEC205 but not with anti-CD14 or anti- $\beta$-actin antibodies.

\section{DEC205 expression in $H$. pylori-positive human gastric mucosa}

We investigated whether DEC205-expressing epithelial cells or macrophages were present within the $H$. pylori-infected gastric mucosa by immunolabeling with an anti-DEC205 antibody. DEC205-positive cells were observed on the surface of gastric pits, between epithelial cells (Figure 2A, red arrows). These DEC205-positive cells also expressed CD14, which confirmed they were macrophages (Figure 2B).

To determine whether DEC205-positive macrophages were induced by $H$. pylori infection, we determined the number of DEC205- and CD14-positive macrophages within the infected mucosa before and after eradication therapy. All CD14-positive cells expressed DEC205, while a few cells that were positive for DEC205 only were deemed to be lymphocytes (B cells) based on their morphology. Eradication therapy markedly reduced the number of DEC205-positive cells (Figure 2C).

\section{Expression of DEC205 mRNA in human PBMCs}

We next investigated whether $H$. pylori affects systemic immunity in humans by comparing levels of DEC-205 transcript in circulating PBMCs before and after stimulation with $H$. pylori cell lysate in healthy individuals and $H$. pylori-infected patients with gastritis. Antigen stimulation with $H$. pylori lysate significantly increased levels of DEC205 transcript in the gastritis patients (Figure 3A) but not the healthy individuals (Figure 3B).

\section{DISCUSSION}

It remains unclear how the immune system directly recognizes $H$. pylori infection and reacts to bacteria in the stomach, where MALT is not normally present. Immune responses normally originate within organized intestinal lymphoid tissue (mostly located in the terminal ileum, including Peyer's patches (PPs) [18]. PPs in the small intestine play critical roles in $H$. pylori-induced gastritis; no gastritis is induced in $H$. pylori-infected mice lacking PPs. Moreover, H. pylori converts to the coccoid form in the anaerobic environment of the small intestine and stimulates the host immune system through PPs. [7]. In the present study, we found that DEC205 is expressed in macrophages of the gastric mucosa. DEC205 is internalized from the cell surface by clathrin-mediated endocytosis, and is targeted to late endosome/lysosomes containing major histocompatibility complex (MHC) class II molecules [19]. DEC205 loads antigens on MHC class II molecules for presentation to $\mathrm{T}$ lymphocytes [16]. Therefore, a specific immune response acting via DEC205-positive APCs such as DCs (i.e., infiltrating macrophages between epithelial cells) and may be present in the $H$. pylori-infected human gastric mucosa.

Mannose receptor DEC205 is expressed on macrophages and binds to a wide variety of microorganisms, including Pneumocystis carinii [20] and Mycobacterium tuberculosis [21]. Here, we revealed an association between DEC205 expression in macrophages and human $H$. pylori infection - i.e., DEC205 may participate in phagocytosis of $H$. pylori surface antigens. For example, urease, HSP60, outer membrane protein (oipA), and lipopolysaccharide (LPS) all reportedly affect host cells $[18,19,22,23]$ and may be phagocytosed by macrophages via DEC205.

In the present study, antibodies against DEC205 effectively inhibited phagocytosis of $H$. pylori by NOMO- 
1 cells. Additionally, Toll-like receptor-mediated signaling reportedly increases DEC205 expression in plasmacytoid DCs [24]. Thus, the innate immune response to several $H$. pylori antigens may induce acquired immunity to $H$. pylori via DEC205. While our study and others [23] suggest $H$. pylori antigens are important for induction of DEC-205 expression, future studies will be need to investigate which antigens are specifically involved.

In sum, we found that $H$. pylori is internalized by macrophages via DEC205, and that the number of DEC205-expressing macrophages is increased in H. pylori-positive gastric mucosa. We also found that DEC205 expression by circulating PBMCs from patients with $H$. pylori-induced gastritis is increased following stimulation with $H$. pylori antigens. These results indicate that DEC205 expression is important for the immune response to $H$. pylori infection.

\section{MATERIALS AND METHODS}

\section{Bacterial strain, antigens, and antibodies}

H. pylori cells (American Type Culture Collection no. 43504) were cultured on brain heart infusion (BHI) agar supplemented with $7 \%$ sterile defibrinated horse blood at $37^{\circ} \mathrm{C}$ in an incubator containing $10 \% \mathrm{CO}_{2}$ at 99\% humidity. After 4 days of incubation, cells were collected in Roswell Park Memorial Institute (RPMI) 1640 medium (Invitrogen, Carlsbad, CA, USA) without fetal bovine serum (FBS) and resuspended at an $\mathrm{OD}_{600}$ of 1.0 , corresponding to approximately $1 \times 10^{8} \mathrm{CFU} / \mathrm{ml}$. to stimulate human peripheral blood mononuclear cells (PBMCs), H. pylori lysate was prepared using ultrasonic sonication of bacteria cultured in BHI broth. The lysate was purified by centrifugation at 20,000 rpm for $20 \mathrm{~min}$, and the supernatant was used as an antigen. An antibody against $H$. pylori urease (30-kDa subunit) was prepared as previously described $[25,26,27]$.

\section{Human tissue and PBMC samples}

Patients $(n=13)$ at Nippon Kokan Fukuyama Hospital with $H$. pylori-positive gastritis underwent eradication therapy [28]. Biopsy samples were subsequently obtained after 3 or 6 months via endoscopy from seven of the 13 patients and stored at $-80^{\circ} \mathrm{C}$ until use; these samples were negative for H. pylori. PBMCs were collected at Okayama University Hospital from healthy individuals $(n=8)$ and patients with gastritis $(n=19)$. PBMCs were cultured with IL-4 (20 ng/ml; PeproTech, Rocky Hill, NJ, USA) and granulocyte macrophage colony-stimulating factor (GM-CSF) (20 ng/ml; PeproTech) and stimulated with $H$. pylori lysate $(5 \mathrm{mg} / \mathrm{ml})$ to induce antigen-specific DCs. Ethical approval to carry out the study was obtained a priori from the Okayama University Ethics Committee (Number 2034).

\section{Cell culture}

The NOMO-1 human monocytic line was obtained from the Japanese Collection of Research Bioresources Cell Bank (Tokyo, Japan) and maintained in RPMI 1640 medium supplemented with $10 \% \mathrm{FBS}$, penicillin (5 IU/ml), streptomycin $(5 \mu \mathrm{g} / \mathrm{ml})$, and amphotericin B $(2.5 \mu \mathrm{g} / \mathrm{ml})$ (MP Biomedicals, Santa Ana, CA, USA) at $37^{\circ} \mathrm{C}$ under an atmosphere of 5\% CO2 at 99\% humidity. Cells were washed three times with RPMI 1640 without antibiotics before each experiment and used at a final concentration of $2 \times 10^{6} \mathrm{cell} / \mathrm{ml}$. To induce macrophage differentiation to DCs, PMA (20 ng/ml) was added to the culture medium $6 \mathrm{~h}$ before the experiment.

\section{Immunocytochemistry}

\section{Cultured cells}

To label engulfed bacteria, NOMO-1 cells $\left(10^{6}\right.$ cell $/ \mathrm{ml}$ ) were pretreated with PMA for $6 \mathrm{~h}$ and then infected with live $H$. pylori $\left(10^{7}\right.$ colony formation unit; $\mathrm{CFU} / \mathrm{ml}$ ) for $1 \mathrm{~h}$. After washing with phosphate-buffered saline (PBS), cells were fixed with 90\% methanol and $10 \%$ glycerol at $-20^{\circ} \mathrm{C}$ for $30 \mathrm{~min}$ and blocked in $10 \%$ fetal calf serum for $1 \mathrm{~h}$ at room temperature. Cells were treated with $0.1 \%$ Triton $\mathrm{X}-100$ in PBS, followed by incubation for $1 \mathrm{~h}$ with anti-DEC205 (BD Biosciences, Franklin Lakes, NJ, USA) and in-house anti-urease (30 $\mathrm{kDa}$ ) antibodies. Immunoreactivity was detected using tetramethylrhodamine (TRITC)-conjugated anti-mouse IgG and fluorescein isothiocyanate (FITC)-conjugated anti-rabbit IgG, respectively. Cells were imaged using a BZ-9000 Biorevo microscope system (Keyence, Osaka, Japan).

\section{Tissue}

Frozen sections of gastric mucosa were fixed in acetone and blocked with $10 \%$ goat serum for $30 \mathrm{~min}$ at room temperature. The blocked sections were incubated first with mouse anti-humanDEC205 and sheep antihuman CD14 antibodies for $1 \mathrm{~h}$ at $37^{\circ} \mathrm{C}$ and then with anti-mouse IgG-TRITC and anti-sheep IgG-FITC for 1 $h$ at room temperature. Nuclei were counterstained with 4',6-diamidino-2-phenylindole. Tissue sections were imaged using a BZ-9000 Biorevo microscope system.

\section{Detection of the intracellular bacterial count}

A phagocytosis assay was carried out as previously described [29], with modifications. NOMO-1 cells $\left(1 \times 10^{6}\right.$ cell $\left./ \mathrm{ml}\right)$ were induced undergo differentiation for $12 \mathrm{~h}$ using PMA. Differentiated cells were infected with $5 \times 10^{7}$ live $H$. pylori $/ \mathrm{ml}$ for $30 \mathrm{~min}$, followed by incubation for 5 min with RPMI 1640 medium containing penicillin $(100 \mathrm{U} / \mathrm{ml})$ and streptomycin $(100 \mathrm{U} / \mathrm{ml})$ to kill 

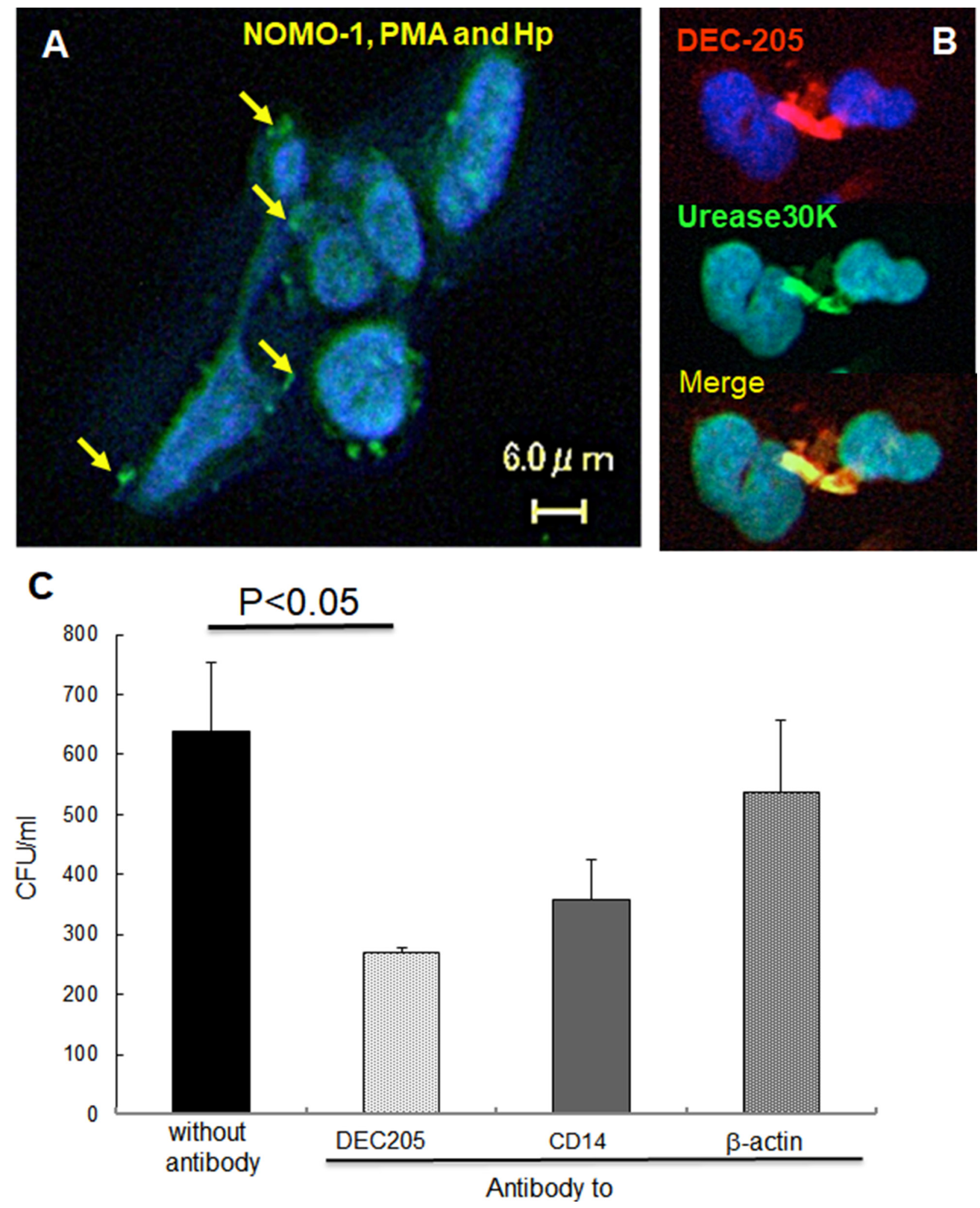

Figure 1: DEC-205's expression on NOMO-1 cells following $\boldsymbol{H}$. pylori infection and effect on phagocytosis. (A) Live $H$. pylori were incubated with NOMO-1 cells for $1 \mathrm{hr}$, and then stained with anti-H. pylori urease antibody. Phagocytosed intracellular bacteria were observed. (B) Double staining with anti-DEC205 and anti-urease $30 \mathrm{kDa}$ antibodies was performed. Anti-DEC205 mouse monoclonal antibody and anti-urease rabbit antibody were detected with TRITC labeled anti-mouse IgG and FITC labeled anti-rabbit IgG, respectively. (C) Inhibition of phagocytosis by pre-treatment with anti-DEC205, anti-CD14, or $\beta$-actin antibodies was measured (mean + SE). AntiDEC205 monoclonal antibody significantly $(p=0.03)$ decreased phagocytosis while CD14 $(p=0.09)$ and $\beta$-actin $(p=0.28)$ were not. 

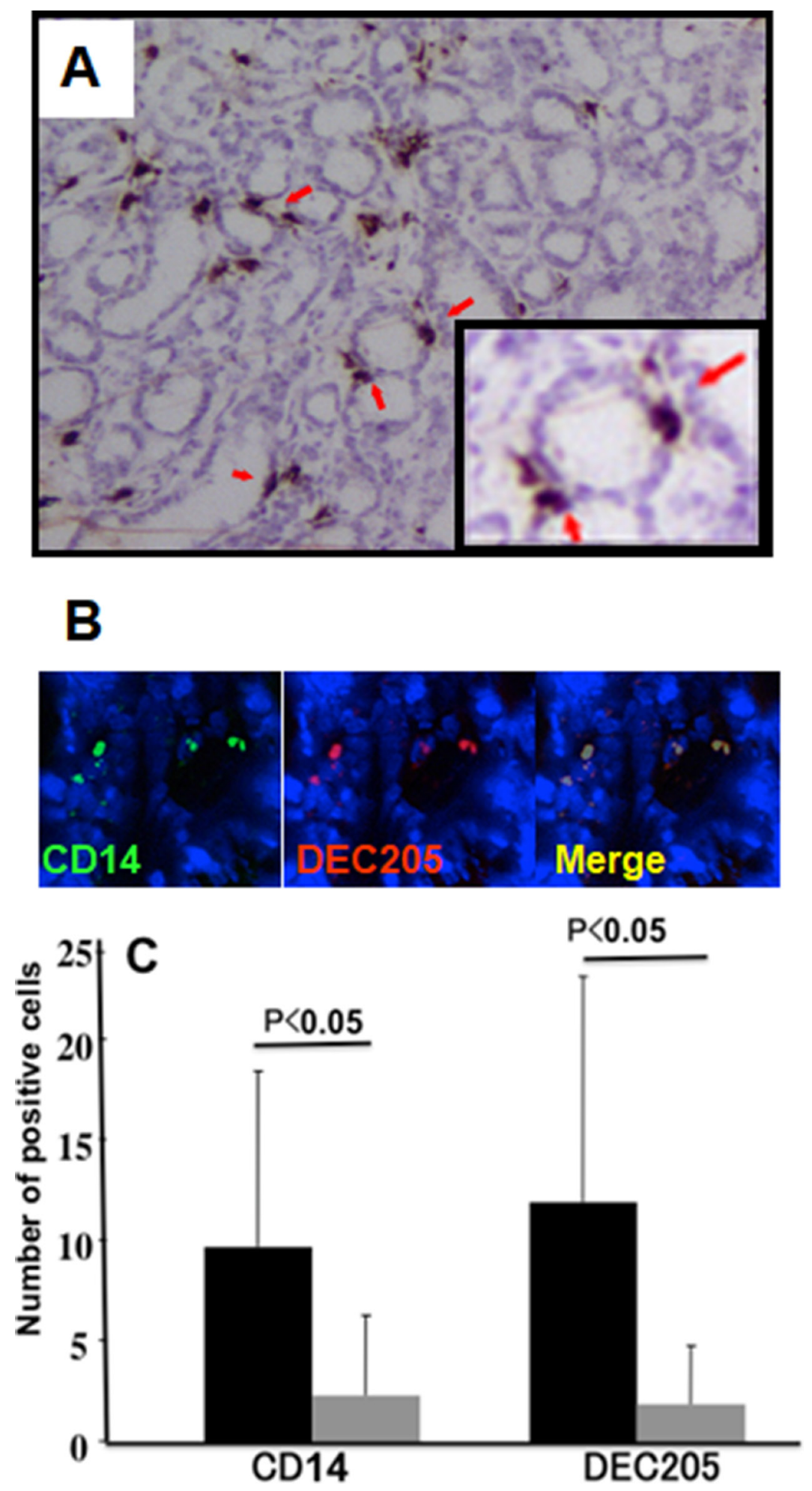

Figure 2: Expression of DEC-205 on macrophages in human gastric mucosa. (A) Samples were stained with an anti-DEC-205 antibody and observe the location of DEC-205-positive cell in the gastric mucosa. (B) Frozen sections of the $H$. pylori-infected gastric mucosa were stained by immunofluorescence double staining. DEC-205 positive cells were stained with mouse monoclonal antibody and detected with a TRITC labeled second antibody. CD14-positive macrophages were detected by anti-CD14 sheep polyclonal antibody by an FITC labeled secondary antibody. More than $90 \%$ cells were double positive for CD14 and DEC205. (C) The number of positive cells of CD14 and DEC205 in each section (mean positive cell number from 5 fields) was counted before and after eradication. H. pylori positive samples are denoted by (black bar: CD14 positive cells; $9.83 \pm 8.80$, DEC-205 positive cells; $11.88 \pm 11.20$ ) and samples obtained after successful eradication are denoted by gray bar: (CD14 positive cells, $2.90 \pm 4.63$ and DEC-205 positive cells $1.88 \pm 2.87$ ). Results were expressed as mean $\pm \mathrm{SE}$, and statistical significance was set at $p<0.05$ (Student's $t$-test). 

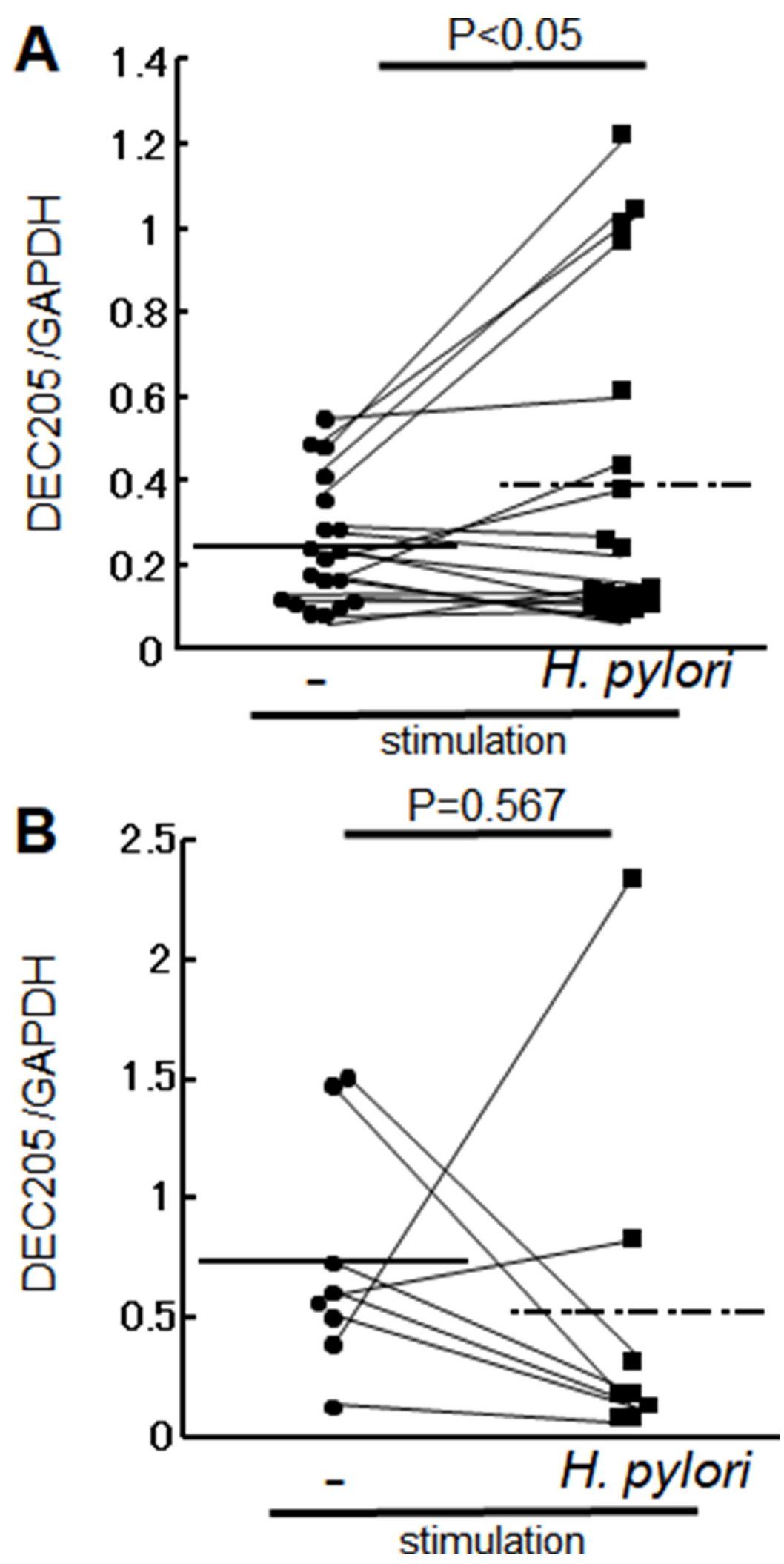

Figure 3: DEC205 mRNA level in PBMCs. PBMCs were collected from $H$. pylori infected patients $(n=19)$ and healthy volunteers $(n=8)$. DEC205 mRNA expression was investigated in both groups with and without stimulation with H. pylori lysate. DEC205 transcript levels in PBMCs are shown as the ratio between DEC205 and the housekeeping gene GAPDH. (A) Transcript levels in patients with gastritis were $0.42 \pm 0.14$ without stimulation and $0.38 \pm 0.38$ with $H$. pylori stimulation $(p<0.05)$. (B) Transcript levels in healthy volunteers were $0.74 \pm 0.49$ without stimulation with $H$. pylori stimulation $(p=0.567)$. 
extracellular bacteria. The cells were then washed four times with RPMI 1640 medium without antibiotics. To harvest the intracellular bacteria, cells were osmotically lysed in distilled water. A $10-\mu 1$ volume of the cell lysate was inoculated on BHI blood agar under microaerophilic conditions. Colonies were counted after culturing for 7 days. For inhibition using antibodies, NOMO1 cells were pretreated for $30 \mathrm{~min}$ with $1 \mu \mathrm{g} / \mathrm{ml}$ anti-DEC205, antiCD14 (R\&D Systems, Minneapolis, MN, USA), or anti- $\beta$ actin (Novus Biologicals, Littleton, CO, USA) antibodies.

\section{Real-time reverse-transcriptase (RT-)PCR}

Total RNA was extracted from PBMCs (approximately $3 \times 10^{5}$ cells) using a RNeasy Mini kit (Qiagen, Valencia, CA, USA). RNA concentration and purity were determined by measuring the absorbance at $260 \mathrm{~nm}$ (A260) and the A260/A280 ratio using a DU-7000 spectrophotometer (Beckman Coulter, Brea, CA, USA). For cDNA synthesis, reverse transcription was carried out using a SuperScript III First-Strand Synthesis system (Invitrogen). To ensure the RNA samples were free of DNA contamination, the assay was performed in duplicate, omitting reverse transcriptase in one set of samples. Real-time PCR was carried out in a Light Cycler Quick System 350S (Roche Diagnostics, Indianapolis, IN, USA). cDNA $(2 \mu \mathrm{l})$ was amplified in $20-\mu 1$ of reaction mixture containing $10 \mu \mathrm{l}$ of SYBR Premix Ex Taq (Takara Bio, Otsu, Japan), $2 \mu$ l of primer for DEC205 (5'-CAAATTCCAAAAGGCCGTACTC-3' and 5'-CACCACTTCTGTCCATCACCA-3') or glyceraldehyde 3-phosphate dehydrogenase (GAPDH) (5'-CAACGGATTTGGTCGTATTGG-3' and 5'-CTGG AAGATGGTGATGGGATTT-3') as a control, and $7.2 \mu \mathrm{l}$ of distilled water. The reaction conditions were as follows: $95^{\circ} \mathrm{C}$ for $30 \mathrm{~s} ; 35$ cycles of $95^{\circ} \mathrm{C}$ for $5 \mathrm{~s}, 55.5^{\circ} \mathrm{C}$ for 10 $\mathrm{s}$, and $72^{\circ} \mathrm{C}$ for $15 \mathrm{~s} ; 65^{\circ} \mathrm{C}$ for $15 \mathrm{~s}$; and $40^{\circ} \mathrm{C}$ for $30 \mathrm{~s}$. Data were analyzed using Light Cycle software v.3.5 (Roche Diagnostics), and the ratio of DEC205/GAPDH mRNA was calculated. Differences between samples were evaluated using Student's $t$ test with significance set at $P<0.05$.

\section{Statistics}

Phagocytosis assays were analyzed using a post-hoc test, and DEC205 mRNA expression levels were analyzed using paired $t$-test. Values of $P<0.05$ was regarded as significant.

\section{Abbreviations}

Peripheral blood mononuclear cell; PBMC, antigenpresenting cell; APC, dendritic cell; DC, phosphatebuffered saline; PBS, interleukin; IL, colony formation unit; CFU.

\section{Author contributions}

$\mathrm{MK}$ and $\mathrm{CH}$ performed the main experiments. $\mathrm{KG}$ maintained the cell cultures. ST collected gastric mucosa samples. YK and KY collected PBMC samples. OM, HO, and KY designed experiments. The article was written mainly by $\mathrm{MK}$ and $\mathrm{KY}$.

\section{CONFLICTS OF INTEREST}

All authors disclose that there are no financial and personal relationships with other people or organizations that could in appropriately influence this work.

\section{FUNDING}

This work was supported by a grant (no.18590425) from the Ministry of Education, Culture, Sports, Science, and Technology of Japan.

\section{REFERENCES}

1. Infection with Helicobacter pylori. IARC Monogr Eval Carcinog Risks Hum. 1994; 61:177-240.

2. Blaser MJ. The bacteria behind ulcers. Sci Am. 1996; 274:104-107.

3. Uemura N, Okamoto S, Yamamoto S, Matsumura N, Yamaguchi S, Yamakido M, Taniyama K, Sasaki N, Schlemper RJ. Helicobacter pylori infection and the development of gastric cancer. N Engl J Med. 2001; 345:784-789.

4. Graham DY. Helicobacter pylori infection is the primary cause of gastric cancer. J Gastroenterol. 2000; 35:90-97.

5. Franchini M, Veneri D. Helicobacter pylori infection and immune thrombocytopenic purpura: an update. Helicobacter. 2004; 9:342-346.

6. Ayada K, Yokota K, Kobayashi K, Shoenfeld Y, Matsuura E, Oguma K. Chronic infections and atherosclerosis. Clin Rev Allergy Immunol. 2009; 37:44-48.

7. Nagai S, Mimuro H, Yamada T, Baba Y, Moro K, Nochi T, Kiyono H, Suzuki T, Sasakawa C, Koyasu S. Role of Peyer's patches in the induction of Helicobacter pylori-induced gastritis. Proc Natl Acad Sci U S A. 2007; 104:8971-8976.

8. Harris PR, Smythies LE, Smith PD, Dubois A. Inflammatory cytokine mRNA expression during early and persistent Helicobacter pylori infection in nonhuman primates. J Infect Dis. 2000; 181:783-786.

9. Sarsfield P, Jones DB, Wotherspoon AC, Harvard T, Wright $\mathrm{DH}$. A study of accessory cells in the acquired lymphoid tissue of Helicobacter gastritis. J Pathol. 1996; 180:18-25.

10. Suzuki T, Kato K, Ohara S, Noguchi K, Sekine H, Nagura $\mathrm{H}$, Shimosegawa T. Localization of antigen-presenting cells in Helicobacter pylori-infected gastric mucosa. Pathol Int. 2002; 52:265-271. 
11. East L, Isacke CM. The mannose receptor family. Biochim Biophys Acta. 2002; 1572:364-386.

12. Heath WR, Belz GT, Behrens GM, Smith CM, Forehan SP, Parish IA, Davey GM, Wilson NS, Carbone FR, Villadangos JA. Cross-presentation, dendritic cell subsets, and the generation of immunity to cellular antigens. Immunol Rev. 2004; 199:9-26.

13. Jiang W, Swiggard WJ, Heufler C, Peng M, Mirza A, Steinman RM, Nussenzweig MC. The receptor DEC205 expressed by dendritic cells and thymic epithelial cells is involved in antigen processing. Nature. 1995; 375:151-155.

14. de Maagd RA, MacKenzie WA, Schuurman HJ, Ritter MA, Price KM, Broekhuizen R, Kater L. The human thymus microenvironment: heterogeneity detected by monoclonal anti-epithelial cell antibodies. Immunology. 1985; 54:745754.

15. Larche M., Lamb JR, O'Hehir RE, Imami-Shita N, Zanders ED, Quint DE, Moqbel R, Ritter MA. Functional evidence for a monoclonal antibody that binds to the human IL-4 receptor. Immunology. 1988; 65:617-622.

16. Larche M., Lamb JR, Ritter MA. A novel T-lymphocyte molecule that may function in the induction of selftolerance and MHC-restriction within the human thymic microenvironment. Immunology. 1988; 64:101-105.

17. Larche M, Lamb JR, Ritter MA. p145-MR6: a novel T cell surface molecule with a role in tolerance to self. Adv Exp Med Biol. 1988; 237:413-417.

18. Wotherspoon AC. Helicobacter pylori infection and gastric lymphoma. Br Med Bull. 1998; 54:79-85.

19. Mahnke K, Guo M, Lee S, Sepulveda H, Swain SL, Nussenzweig M, Steinman RM. The dendritic cell receptor for endocytosis, DEC205, can recycle and enhance antigen presentation via major histocompatibility complex class II-positive lysosomal compartments. J Cell Biol. 2000; 151:673-684.

20. Stehle SE, Rogers RA, Harmsen AG, Ezekowitz RA. A soluble mannose receptor immunoadhesin enhances phagocytosis of Pneumocystis carinii by human polymorphonuclear leukocytes in vitro. Scand J Immunol. 2000; 52:131-137.
21. Schlesinger LS. Macrophage phagocytosis of virulent but not attenuated strains of Mycobacterium tuberculosis is mediated by mannose receptors in addition to complement receptors. J Immunol. 1993; 150:2920-2930.

22. Andersen LP. Colonization and infection by Helicobacter pylori in humans. Helicobacter. 2007; 12:12-15.

23. Yamaoka Y. Mechanisms of disease: Helicobacter pylori virulence factors. Nat Rev Gastroenterol Hepatol. 2010; 7:629-641.

24. Tel J, Benitez-Ribas D, Hoosemans S, Cambi A, Adema GJ, Figdor CG, Tacken PJ, de Vries IJ. DEC-205 mediates antigen uptake and presentation by both resting and activated human plasmacytoid dendritic cells. Eur J Immunol. 2011; 41:1014-1023.

25. Takenaka R, Yokota K, Ayada K, Mizuno M, Zhao Y, Fujinami Y, Lin SN, Toyokawa T, Okada H, Shiratori Y, Oguma K. Helicobacter pylori heat-shock protein 60 induces inflammatory responses through the Toll-like receptor-triggered pathway in cultured human gastric epithelial cells. Microbiology. 2004; 150:3913-3922.

26. Zhao Y, Yokota K, Ayada K, Yamamoto Y, Okada T, Shen L, Oguma K. Helicobacter pylori heat-shock protein 60 induces interleukin-8 via a Toll-like receptor (TLR)2 and mitogen-activated protein (MAP) kinase pathway in human monocytes. J Med Microbiol. 2007; 56:154-164.

27. Yunoki N, Yokota K, Mizuno M, Kawahara Y, Adachi M, Okada H, Hayashi S, Hirai Y, Oguma K, Tsuji T. Antibody to heat shock protein can be used for early serological monitoring of Helicobacter pylori eradication treatment. Clin Diagn Lab Immunol. 2000; 7:574-577.

28. Take S, Mizuno M, Ishiki K, Nagahara Y, Yoshida T, Yokota K, Oguma K, Okada H, Shiratori Y. The effect of eradicating Helicobacter pylori on the development of gastric cancer in patients with peptic ulcer disease. Am J Gastroenterol. 2005; 100:1037-1042.

29. Athamna A, Ofek I, Keisari Y, Markowitz S, Dutton GG, Sharon N. Lectinophagocytosis of encapsulated Klebsiella pneumoniae mediated by surface lectins of guinea pig alveolar macrophages and human monocyte-derived macrophages. Infect Immun. 1991; 59:1673-1682. 